\title{
Role of WNT signalling in the determination of human mesenchymal stem cells into preadipocytes
}

\author{
Matthias Laudes \\ Department of Internal Medicine II, University of Cologne, Kerpener Strasse 62, 50924 Cologne, Germany \\ (Correspondence should be addressed to M Laudes who is now at Department of Internal Medicine I, University of Kiel, Arnold-Heller-Strasse, \\ 24105 Kiel, Germany; Email: matthias.laudes@uk-sh.de)
}

\begin{abstract}
The development of obesity is characterised not only by increased storage of lipids in existing fat cells but also by the generation of new adipocytes from progenitor cells. This process, called adipogenesis, can be divided into two related steps. First, during determination, multipotent mesenchymal stem cells commit to preadipocytes. These cells exhibit similar morphology compared with stem cells; however, they are committed to the adipogenic lineage and are not longer able to transform into osteoblasts, myocytes or chondrocytes. Secondly, during differentiation, preadipocytes become mature fat cells. As in other developmental processes, adipogenesis is tightly regulated at a molecular level by several transcription factors. Within the last decade, it has also become clear how the activity of these transcription factors is coordinated by extracellular signals. In this respect, secreted WNT signalling molecules are particularly important. Several members of the WNT family have been shown to inhibit early steps of adipogenesis. Conversely, endogenous inhibitors of WNT signalling were found to promote generation of adipocytes, indicating a fundamental role of these bioactive peptides in adipogenesis. From a pathophysiological point of view, it is of interest that polymorphisms in genes of the WNT signalling system have been associated with the development of obesity and type 2 diabetes in humans. Moreover, recent findings indicate that certain WNT molecules are involved in the so-called low-grade inflammation of adipose tissue, which is crucial in the development of obesity-associated insulin resistance. These important findings in nutritional and metabolic medicine will be summarised in the present review.
\end{abstract}

Journal of Molecular Endocrinology (2011) 46, R65-R72

\section{Introduction}

During the last century, a dramatic increase in the prevalence of obesity and its associated metabolic diseases such as type 2 diabetes has been noticed in most developed nations around the globe. Therefore, biomedical research into the molecular regulation of metabolism in response to nutritional factors has become increasingly important. High caloric intake and/or decreased energy expenditure results in a state of positive energy balance. This normally drives an increase in adipose tissue mass by two distinct mechanisms (Arner et al. 2010). First, excess energy is stored as additional triglycerides in existing adipocytes resulting in enlargement of these cells, which is called hypertrophy. Secondly, if the number of fat cells is not sufficient to store increasing amounts of triglycerides, new adipocytes are generated by adipogenesis of mesenchymal precursor cells in a process described as hyperplasia. As long as adipose tissue is able to increase the capacity to store excessive energy by hypertrophy and/or hyperplasia, metabolic abnormalities are rare.
However, if adipose tissue is unable to recruit new fat cells, the size of the existing adipocytes may abnormally increase, which is known to be associated with whole-body insulin resistance (Klöting et al. 2010). Furthermore, disturbances in the generation of new fat cells may also result in ectopic lipid storage in liver and skeletal muscle (Sethi \& Vidal-Puig 2007), which is known to be associated with impaired insulin signalling in these metabolically important tissues (Savage et al. 2005). From this point of view, abnormalities in adipogenesis are crucial in the development of obesity-associated co-morbidities, such as insulin resistance and type 2 diabetes.

Molecular research during the last decade revealed that many wingless-type MMTV integration site family members (WNT) signalling molecules act as negative regulators of adipogenesis in cell lines, rodents and humans. In general, it has been suggested that inhibition of WNT signalling is required to induce mesenchymal stem cells to undergo adipogenesis (Christodoulides et al. 2009). Besides that, induction of WNT inhibitors has been shown to be important to 
ensure a sufficient differentiation process (Lagathu et al. 2010). In this review, the role of WNT molecules as regulators of adipogenesis will be summarised, and their implication in the pathogenesis of obesity and type 2 diabetes will be discussed.

\section{Molecular regulation of adipogenesis}

Adipogenesis is a tightly regulated developmental process, which can be divided into two related steps (Bowers \& Lane 2008). During the so-called 'determination' phase, mesenchymal stem cells commit to preadipocytes (Rosen \& MacDougald 2006). The main difference between these two types of mesenchymal cells is that stem cells are multipotent and can differentiate into adipocytes, osteoblasts, myocytes and chondrocytes, whereas preadipocytes are committed to the adipogenic lineage. Following determination, preadipocytes then become mature fat cells, in what is referred to as the 'differentiation' process. Although extensive research has been undertaken in the past on the molecular regulation of adipogenesis, most knowledge exists about the differentiation, whereas the determination process is poorly understood (Bowers \& Lane 2008). One reason is that most studies have been performed using murine 3T3-L1 cells, which are preadipocytes already committed to the adipogenic lineage and are therefore inappropriate for experiments on the determination process.

Induction of adipogenesis in both mesenchymal stem cells and committed preadipocytes by a hormonal cocktail (consisting of at least insulin, dexamethasone and 1-methyl-3-isobutylxanthine) results in the activation of a cascade of transiently expressed transcription factors (Rosen \& Spiegelman 2000, Laudes et al. 2004, 2008). Of these, C/CAAT enhancer-binding protein $(\mathrm{C} / \mathrm{EBP})-\alpha$ and $\mathrm{C} / \mathrm{EBP}-\beta$ and peroxisome proliferator activator receptor (PPAR) $-\gamma$ are particularly important, since they increase the promoter activity of genes essential for the adipocyte phenotype (Rosen \& Spiegelman 2000). However, the signalling cascades inducing $\mathrm{C} / \mathrm{EBPs}$ and PPAR- $\gamma$ themselves have not been known in detail for years. Fortunately, recent advances in biomedical research during the last decade revealed that both $\mathrm{C} / \mathrm{EBP}$ and PPAR- $\gamma$ activities are regulated by canonical and non-canonical WNT signalling in mesenchymal cells.

\section{Canonical and non-canonical WNT signalling}

WNT signalling was first described in Drosophila and is a highly conserved pathway found in several organisms from nematodes to mammals (Wainwright et al. 1988). The name arises from the polarity gene 'wingless' in
Drosophila and its eukaryotic homologue 'int-1' (Rijsewijk et al. 1987). The pathway is crucial in many developmental processes especially stem cell biology. WNT molecules constitute a 19-member family of secreted, cysteine-rich glycopeptides that act in an autocrine or a paracrine manner (Logan \& Nusse 2004). WNT molecules exert their effects by signalling through different 'canonical' and 'non-canonical' pathways (Fig. 1). The canonical WNT signalling pathway is also referred to as 'WNT/ $\beta$-catenin dependent' and the noncanonical pathway as 'WNT/ $\beta$-catenin independent', because the cytosolic protein $\beta$-catenin exhibits a crucial role in the canonical signalling (Cadigan \& Liu 2006). In the absence of WNT molecules, a degradation complex consisting of AXIN, the adenomatous polyposis coli (APC) protein, and glycogen synthase kinase $3 \beta$ (GSK3 $\beta$ ) exerts enzymatic activity. As a result, cytosolic $\beta$-catenin undergoes ubiquitination followed by protosomal degradation. Binding of specific WNT molecules to a receptor complex consisting of a frizzled receptor (FZ) and a low-density lipoprotein receptorrelated protein (LRP) co-receptor disrupts the degradation complex and consequently results in stabilisation of cytosolic free $\beta$-catenin. $\beta$-Catenin then translocates into the nucleus, binds to transcription factors of the lymphoid enhancer-binding factor/T-cellspecific transcription factor (LEF/TCF) family and activates promoters of WNT target genes. In contrast to the detailed understanding of the canonical pathway, at present, non-canonical WNT signalling is poorly defined. At least two different non-canonical cascades exist (Sethi \& Vidal-Puig 2010). In the WNT-cGMP/ $\mathrm{Ca}^{2+}$ pathway, specific WNT molecules and FZ isoforms trigger an intracellular $\mathrm{Ca}^{2+}$ release through activation of a heterotrimeric GTP-binding protein. This in turn activates the $\mathrm{Ca}^{2+}$-sensitive kinase calcium/calmodulindependent kinase II (CAMKII) and the protein kinase C. Activation of these cascades results, for example, in the induction of the transcription factor nuclear factor of activated T-cells, which regulates the promoter activity of several WNT target genes (Semenov et al. 2007). Besides this $\mathrm{Ca}^{2+}$-dependent pathway, signalling of distinct WNT family members is also mediated by the c-Jun N-terminal kinase (JNK). The JNK cascade can be activated by certain FZ receptors or by the receptor tyrosine kinase-like orphan receptor (ROR; Semenov et al. 2007). JNK exists in three isoforms (JNK1, 2 and 3), which are generated by alternative splicing. Upon induction of JNK by FZ or ROR receptors, the kinase phosphorylates the protein c-Jun among others, which forms the transcription factor complex AP-1 together with c-fos resulting in the activation of target gene promoters (Bogoyevitch et al. 2010).

WNT signalling is also influenced by potent antagonists, which exert their inhibitory effects at different points of the system (Kawano \& Kypta 2003). 

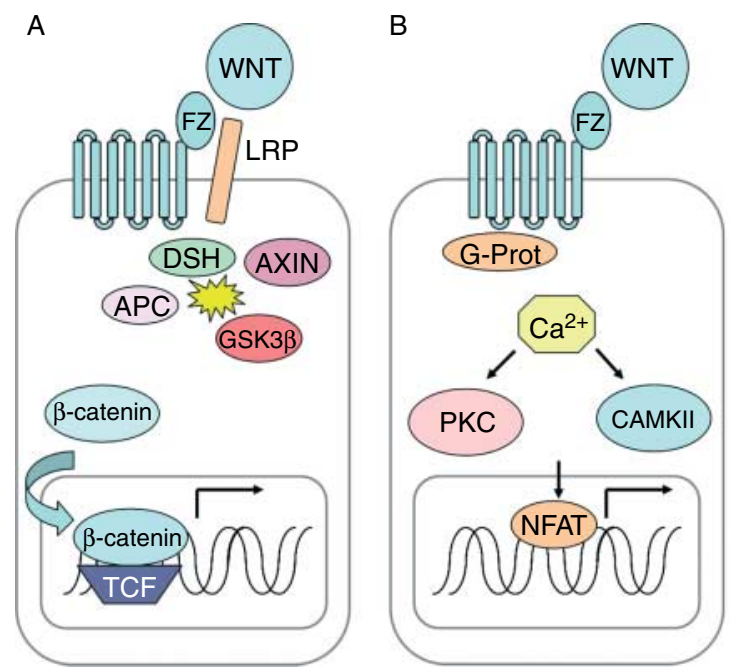

C

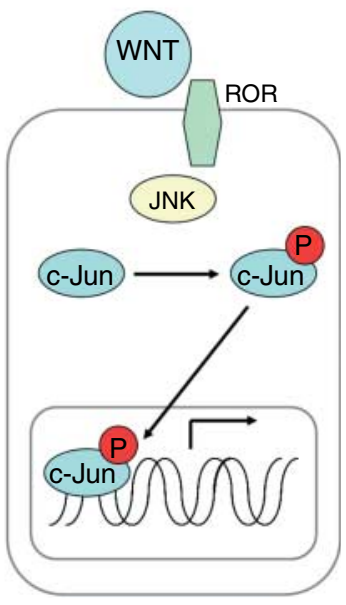

Figure 1 WNT signalling pathways. (A) Canonical WNT signalling: upon WNT binding to a receptor complex consisting of a frizzled receptor (FZ) and a low-density lipoprotein-related peptide (LRP) co-receptor, a degradation complex of adenomatous polyposis coli (APC) protein, AXIN and GSK3 $\beta$ disintegrates resulting in the stabilisation of cytosolic $\beta$-catenin. The latter then is stabilised and translocates into the nucleus, where it binds to transcription factors of the lymphoid enhancer-binding factor/T-cell-specific transcription factor (LEF/TCF) family resulting in the activation of target gene promoters. (B) $\mathrm{Ca}^{2+}$-dependent non-canonical WNT signalling: WNT binding to a specific receptor induces an intracellular $\mathrm{Ca}^{2+}$ release through activation of a $\mathrm{G}$ protein. This in turn activates the $\mathrm{Ca}^{2+}$-sensitive kinase calcium/calmodulin-dependent kinase II (CAMKII) and the protein kinase C (PKC) thereby inducing transcription factors such as nuclear factor of activated T-cells (NFAT) followed by up-regulation of target gene expression. (C) JNK-dependent non-canonical WNT signalling: the JNK cascade can be activated by specific WNT molecules binding to either FZ receptors or receptor tyrosine kinase like-orphan receptor (ROR). JNK, for example, phosphorylates the protein c-Jun, which forms a transcription factor together with $\mathrm{c}$-fos resulting in the activation of target gene promoters.

Secreted frizzled-related proteins (SFRP) and the WNT inhibitory factor-1 (WIF1) are soluble factors that directly bind WNT molecules and thereby sequester them from their membrane-bound receptors. By contrast, the Dickkopf $(D K K)$ family members bind with high affinity to the LRP co-receptors, which results in the disruption of the WNT receptor complex. Recently, it also became evident that the WNT signalling pathway can be influenced by intracellular mediators. For example, the DAPPER1/FRODO1 (DACT1) protein has been shown to interact with the protein Dishevelled thereby inhibiting conduction of the signal from the FZ/LRP receptor complex (Zhang et al. 2006). DACT1 also has been shown to coordinate effects on gene expression that selectively alter intracellular and paracrine/autocrine components of the canonical signalling pathway during adipogenesis (Lagathu et al. 2009). Furthermore, canonical WNT signalling can be antagonised within the nucleus as shown for the proteins chibby and chop. These factors interfere with LEF or TCF transcription factors thereby inhibiting the expression of WNT target genes (Takemaru et al. 2003, Horndasch et al. 2006).

\section{WNT molecules in the determination of preadipocytes}

The first study implicating a role for canonical WNT signalling in adipogenesis was published in the year 2000 (Ross et al. 2000). In this report, it was shown that WNT10B maintains preadipocytes in an undifferentiated state through inhibition of the pro-adipogenic transcription factors $\mathrm{C} / \mathrm{EBP}-\alpha$ and PPAR- $\gamma$. This inhibitory effect has been confirmed by several independent groups (Bennett et al. 2003, Kawai et al. 2007). Furthermore, when WNT signalling was prevented by overexpression of a dominant-negative TCF4, preadipocytes underwent enhanced differentiation, indicating that the inhibitory effect of WNT10B on adipogenesis is mediated via the canonical pathway (Ross et al. 2000). In addition, disruption of WNT signalling in vitro caused transdifferentiation of myocytes into adipocytes (Ross et al. 2000). This important finding in this initial report demonstrated that WNT signalling is essential in mesodermal cell fate determination. On a molecular level, it was later 
shown that WNT molecules acting via the canonical pathway activate the expression of chicken ovalbumin upstream promoter transcription factor II (COUPTFII), which recruits the silencing mediator of retinoid and thyroid hormone receptors (SMRT) co-repressor complex to the first introns of PPAR- $\gamma$ (Okamura et al. 2009). This maintains the chromatin in a hypoacetylated state, which represses the expression of this proadipogenic transcription factor. Furthermore, PPAR- $\gamma$ can also be influenced by the non-canonical pathway. For example, WNT5A can activate a CAMKII-dependent signalling cascade and induce the Nemo-like kinase (NLK), which phosphorylates a histone methyl transferase. This leads to the formation of a co-repressor complex that inactivates PPAR- $\gamma$ function through histone H3-K9 methylation (Takada et al. 2007).

The role of canonical WNT signalling in adipogenesis has also been examined at a physiological level. Transgenic mice overexpressing WNT10B from the adipocyte-specific FABP4 promoter have less adipose tissue when maintained on a normal chow diet and are resistant to diet-induced obesity (Wright et al. 2007). Furthermore, these mice do not gain significant body weight even on the $o b / o b$ background. Strikingly, compared with normal $o b / o b$ mice, which are hyperphagic due to leptin deficiency and therefore develop profound obesity, FABP $4-\mathrm{WNT} 10 \mathrm{~B} / o b / o b$ mice at 8 weeks of age exhibited a $70 \%$ reduction in visceral and subcutaneous adipose tissue mass (Wright et al. 2007). Besides these data on canonical WNT10B, genetic variants in non-canonical WNT5A have also been associated with the development of obesity in animal models (Almind \& Kahn 2004), suggesting that both signalling pathways are important in adipose tissue formation in vivo. In 2006, a pathophysiological role of canonical WNT10B signalling could also be demonstrated in humans. Sequencing the WNT1OB gene in two independent populations with more than 200 obese individuals identified a proband with early onset obesity carrying a C256Y mutation in the WNT10B gene, which abrogated the ability of WNT10B to activate the canonical signalling pathway (Christodoulides et al. 2006a). As a consequence, adipogenesis is no longer inhibited, which might explain the occurrence of severe obesity. Of importance, the mutation was not detected in 600 healthy controls and co-segregated with the obese phenotype in the patients' family.

Besides white adipose tissue, which comprises the majority of fat cells and whose main function is to store energy and to participate in the regulation of metabolism, rodents and humans also contain so-called brown adipose tissue (Tseng et al. 2004, Cypess et al. 2009). The brownish colour of this fat depot, which is mainly localised intrascapular, comes from the high mitochondrial content. It is thought that the main function of brown adipose tissue is to contribute to energy expenditure through regulated heat production and thereby defend against a decrease in body temperature. Although C/EBPs and PPAR- $\gamma$ are also important transcriptional regulators in brown adipogenesis, there are some unique features of brown adipocytes. For example, these cells express high levels of the uncoupling protein-1, which uncouples respiration from ATP synthesis (Hagen \& Vidal-Puig 2002). During the last several years, it has been shown that the development of brown fat tissue is also significantly inhibited by canonical WNT signalling (Kang et al. 2005). However, it should also be mentioned that mitochondrial biogenesis itself was found to be increased in response to WNT molecules (An et al. 2010, Yoon et al. 2010). In summary, these molecular, cellular and physiological findings clearly demonstrate a crucial role for WNT signalling in rodent and human white and brown adipogenesis.

It has also become clear in recent years that WNT signalling has a unique role in controlling adipogenesis versus the development into other mesenchymal lineages. As shown in several reports, osteogenesis, myogenesis and chondrogenesis are all promoted, while adipogenesis is the only mesenchymal developmental process, which is inhibited by WNT molecules (Zhou et al. 2004, 2007, Akimoto et al. 2005, Kennell \& MacDougald 2005, Kirton et al. 2007, Shang et al. 2007a,b, Schilling et al. 2008). For example, canonical WNT3A signalling in mesenchymal stem cells resulted in the induction of several pro-myogenic factors such as PAX7, MYOD and myogenin. Interestingly, at the same time, $\mathrm{C} / \mathrm{EBP}-\alpha$ and PPAR- $\gamma$ expression was reduced in these cells, indicating that WNT3A is an important regulator in the determination of stem cells into myocytes versus adipocytes (Shang et al. 2007a,b). In terms of osteogenesis, our own experiments as well as the studies performed by independent groups showed that non-canonical WNT5A signalling induces multipotent mesenchymal stem cells to undergo osteogenesis, while simultaneously adipogenesis is inhibited (Arnsdorf et al. 2009, Bilkovski et al. 2010, Santos et al. 2010). Furthermore, the osteopontin promoter was found to be up-regulated by WNT5A, suggesting a molecular mechanism by which this WNT family member exerts pro-osteogenic effects (Bilkovski et al. 2010). Finally, canonical WNT signalling was found to enhance chondrogenesis in pericyte pellet cultures in the presence of transforming growth factor- $\beta 3$ as demonstrated by SOX9 expression and glycosaminglycan accumulation into the matrix (Kirton et al. 2007). The importance of WNT signalling molecules in regulation of the fate determination from adipogenesis towards osteogenesis has also been shown in in vivo systems. For example, the FABP4-WNT10B transgenic mice mentioned above not only exhibit reduced adipose tissue mass but also their femurs have almost four times 
as much bone mass in the distal metaphyses and are mechanically stronger (Bennett et al. 2005). FABP4WNT10B mice maintain elevated bone mass for at least 23 months of age, which reflects reduced senile osteoporosis. Furthermore, they are protected from bone loss due to oestrogen deficiency. A second important in vivo model is Wnt $10 b^{-/-}$mice, which exhibit decreased trabecular bone mass and reduced serum levels of osteocalcin (Bennett et al. 2005). In summary, these data clearly indicate that WNT signalling is crucial in the regulation of the cell fate determination of multipotent stem cells into different mesenchymal lineages.

While WNT molecules are important in the determination of multipotent stem cells into preadipocytes, WNT antagonists exert a crucial role during the differentiation process of preadipocytes into mature fat cells. For instance, SFRP1 is induced during adipogenesis and constitutive overexpression of SFRP1 in vitro promoted adipogenic differentiation by inhibition of canonical WNT signalling (Lagathu et al. 2010). In complete agreement with these in vitro findings, SFRP1 was shown to be expressed at higher levels in mature fat cells compared with preadipocytes in humans and, of importance, SFRP1 expression in adipose tissue was shown to be increased in patients with mild obesity (Lagathu et al. 2010). Also, the expression of DKK1 was shown to be induced at the beginning of the human adipogenic differentiation process ex vivo. In addition, a constitutive DKK1 overexpression promoted (Christodoulides et al. 2006b) while a DKK1 knockdown by siRNA inhibited adipogenesis (Park et al. 2008). From a pharmacological point of view, it is important to mention that thiazolidinediones, a class of oral antidiabetic drugs, rapidly increased DKK1 protein levels and secretion in adipocytes (Gustafson et al. 2009). Interestingly, DKK1 was detected during human but not rodent adipogenesis, suggesting species specificity of this bioactive factor (Christodoulides et al. 2006b). Besides these classical WNT inhibitors, recently it has been shown that microRNA molecules are able to interfere with WNT signalling. By genetic screening in Drosophila, miR-8 was identified to potently antagonise WNT signalling and to repress TCF protein levels. In the same report, the mammalian homologues of miR- 8 were shown to promote adipogenesis of marrow
Lean

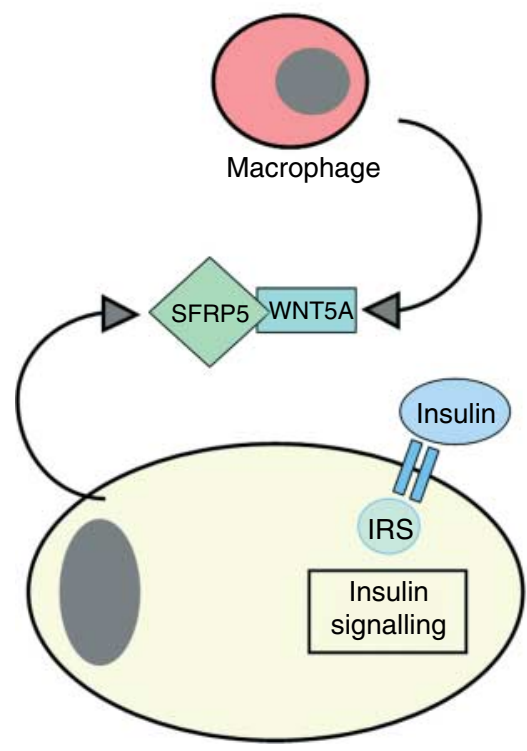

Adipocyte
Obesity and type 2 diabetes
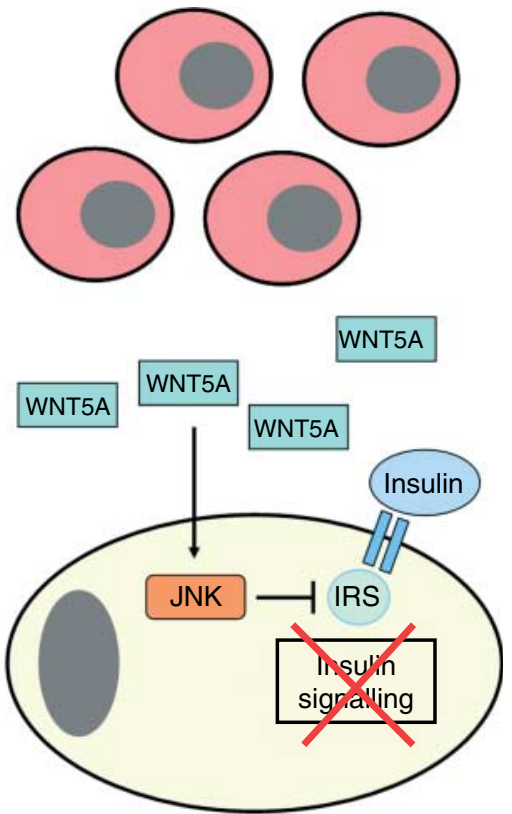

Figure 2 Model of WNT molecules being involved in low-grade inflammation of adipose tissue: in a lean and healthy subject, the number of macrophages in adipose tissue is low. These cells secrete anti-adipogenic WNT5A, which is neutralised by SFRP5 released by healthy adipocytes. In obese and type 2 diabetic subjects, the number of macrophages is increased. In addition, adipocytes from such subjects secrete less SFRP5, resulting in increase in WNT5A activity in adipose tissue. This in turn induces insulin resistance of mature adipocytes via JNK interfering with insulin receptor substrate (IRS) 1 and also impairs generation of novel adipocytes by inhibiting adipogenesis of mesenchymal precursor cells. 
stromal cells, indicating an evolutionary conserved role of miR- 8 family members in regulating WNT signalling and adipogenesis (Kennell et al. 2008).

\section{WNT molecules in the pathogenesis of human obesity and type 2 diabetes}

Motivated by increasing knowledge about WNT signalling in the development of human adipose tissue, several genetic studies were performed to examine whether polymorphisms in WNT genes are associated with the development of obesity and type 2 diabetes in humans. In one report, using a candidate gene approach, a heterozygous mutation in the WNT1OB gene was found in a proband with early onset obesity but not in 600 healthy controls (Christodoulides et al. 2006a). Although this clearly suggests a relevant role of WNT signalling molecules in the pathogenesis of obesity in humans, this single mutation does not represent a common mechanism in the large preponderance of subjects suffering from obesity. In case of type 2 diabetes, large-scale genetic screening approaches resulted in the identification of two important genes. First, two independent studies with more than hundred patients each reported a significant association of common single nucleotide polymorphisms (SNPs) in the WNT5B gene with type 2 diabetes in humans (Kanazawa et al. 2004, Salpea et al. 2009). Most importantly, several independent genetic studies revealed that variants in the transcription factor 7-like 2 (TCF7L2) gene are associated with a significant risk for type 2 diabetes (Grant et al. 2006, Scott et al. 2006, 2007). TCF7L2, also known as TCF4, is part of the canonical WNT signalling pathway (Smith 2007). However, studies on a potential mechanism whereby TCF7L2 might influence diabetes risk revealed that pathogenetic SNPs are related to impaired insulin secretion and disturbed effects of the incretin system, which suggests that WNT signalling in humans is not only important in adipose tissue development but also in pancreatic islet biology (Lyssenko et al. 2007).

\section{WNT molecules and low-grade inflammation of adipose tissue}

Infiltration of adipose tissue by macrophages and lymphocytes has been associated with insulin resistance (Kintscher et al. 2008, Blüher et al. 2009). It is believed that these inflammatory cells alter adipogenesis via secretion of pro-inflammatory cytokines (Sethi \& Hotamisligil 1999), which may result in impaired hyperplasia of adipose tissue in response to high caloric intake. As a consequence, an increasing amount of triglycerides is stored in enlarged adipocytes known to be associated with insulin resistance. A recent report from our own group suggests that macrophages not only influence adipogenesis of mesenchymal precursor cells via pro-inflammatory cytokines but also by secretion of WNT5A (Bilkovski et al. 2011). Interestingly, an independent study identified SFRP5, a known antagonist of WNT5A, as an anti-inflammatory adipokine whose secretion by adipocytes is perturbed in models of obesity and type 2 diabetes (Ouchi et al. 2010; Fig. 2). Thus, WNT signalling might have a fundamental role in the interaction of adipocytes and inflammatory cells in adipose tissue of patients with obesity and type 2 diabetes.

\section{Conclusion}

Within the last 10 years, it has become evident that WNT signalling molecules are important key regulatory factors that play a unique role in the determination of multipotent mesenchymal stem cells into preadipocytes. Furthermore, increasing evidence suggests that in later stages of adipogenesis, WNT inhibitors are necessary to maintain WNT signalling in an inactive state. These effects at the cellular and molecular level are crucial in the pathogenesis of obesity and type 2 diabetes as illustrated both by animal models and by several genetic studies in humans. Finally, recent data suggest that these bioactive molecules are not only important in the regulation of differentiation processes but are also involved in coordinating the activity of inflammatory cells within adipose tissue. These latest findings in particular are likely to open an interesting avenue of biomedical research, which may result in the development of novel therapeutic approaches to treat these important metabolic diseases.

\section{Declaration of interest}

The author declare that there is no conflict of interest that could be perceived as prejudicing the impartiality of the review reported.

\section{Funding}

This review did not receive any specific grant from any funding agency in the public, commercial or not-for-profit sector.

\section{Acknowledgements}

I would like to thank my long-lasting friends Robert K Semple and Jaswinder K Sethi from the University of Cambridge for proof reading the manuscript.

\section{References}

Akimoto T, Ushida T, Miyaki S, Akaogi H, Tsuchiya K, Yan Z, Williams RS \& Tateishi T 2005 Mechanical stretch inhibits myoblastto-adipocyte differentiation through Wnt signaling. Biochemical and Biophysical Research Communications 329 381-385. (doi:10.1016/ j.bbrc.2005.01.136) 
Almind K \& Kahn CR 2004 Genetic determinants of energy expenditure and insulin resistance in diet-induced obesity in mice. Diabetes 53 3274-3285. (doi:10.2337/diabetes.53.12.3274)

An JH, Yang JY, Ahn BY, Cho SW, Jung JY, Cho HY, Cho YM, Kim SW, Park KS, Kim SY et al. 2010 Enhanced mitochondrial biogenesis contributes to Wnt induced osteoblastic differentiation of C3H10T1/2 cells. Bone 47 140-150. (doi:10.1016/j.bone.2010.04.593)

Arner E, Westermark PO, Spalding KL, Britton T, Rydén M, Frisén J, Bernard S \& Arner P 2010 Adipocyte turnover: relevance to human adipose tissue morphology. Diabetes 59 105-109. (doi:10.2337/ db09-0942)

Arnsdorf EJ, Tummala P \& Jacobs CR 2009 Non-canonical Wnt signaling and $\mathrm{N}$-cadherin related $\beta$-catenin signaling play a role in mechanically induced osteogenic cell fate. PLoS ONE 4 e5388. (doi:10.1371/journal.pone.0005388)

Bennett CN, Hodge CL, MacDougald OA \& Schwartz J 2003 Role of Wnt10b and $\mathrm{C} / \mathrm{EBP} \alpha$ in spontaneous adipogenesis of 243 cells. Biochemical and Biophysical Research Communications 30 12-16. (doi:10.1016/S0006-291X(03)00092-5)

Bennett CN, Longo KA, Wright WS, Suva LJ, Lane TF, Hankenson KD \& MacDougald OA 2005 Regulation of osteoblastogenesis and bone mass by Wnt10b. PNAS 102 3324-3329. (doi:10.1073/pnas. 0408742102)

Bilkovski R, Schulte DM, Oberhauser F, Gomolka M, Udelhoven M, Hettich MM, Roth B, Heidenreich A, Gutschow C, Krone W et al. 2010 Role of WNT-5a in the determination of human mesenchymal stem cells into preadipocytes. Journal of Biological Chemistry $\mathbf{2 8 5}$ 6170-6178. (doi:10.1074/jbc.M109.054338)

Bilkovski R, Schulte DM, Oberhauser F, Mauer J, Hample B, Gutschow C, Krone W \& Laudes M 2011 Adipose tissue macrophages inhibit adipogenesis of mesenchymal precursor cells via wnt-5a in humans. International Journal of Obesity (In Press). (doi:10.1038/ijo.2011.6)

Blüher M, Bashan N, Shai I, Harman-Boehm I, Tarnovscki T, Avinaoch E, Stumvoll M, Dietrich A, Klöting N \& Rudich A 2009 Activated Ask1-MKK4-p38MAPK/JNK stress signaling pathway in human omental fat tissue may link macrophage infiltration to whole-body insulin sensitivity. Journal of Clinical Endocrinology and Metabolism 94 2507-2515. (doi:10.1210/jc.2009-0002)

Bogoyevitch MA, Ngoei KR, Zhao TT, Yeap YY \& Ng DC 2010 c-Jun N-terminal kinase (JNK) signaling: recent advances and challenges. Biochimica et Biophysica Acta 1804 463-475. (doi:10.1016/j.bbapap. 2009.11.002)

Bowers RR \& Lane MD 2008 Wnt signaling and adipocyte lineage commitment. Cell Cycle 7 1191-1196. (doi:10.4161/cc.7.9.5815)

Cadigan KM \& Liu YI 2006 Wnt signaling: complexity at the surface. Journal of Cell Science 119 395-402. (doi:10.1242/jcs.02826)

Christodoulides C, Scarda A, Granzotto M, Milan G, Dalla Nora E, Keogh J, De Pergola G, Stirling H, Pannacciulli N, Sethi JK et al. 2006 $a$ WNT10B mutations in human obesity. Diabetologia 49 678-684. (doi:10.1007/s00125-006-0144-4)

Christodoulides C, Laudes M, Cawthorn WP, Schinner S, Soos M, O'Rahilly S, Sethi JK \& Vidal-Puig A 2006 $b$ The Wnt antagonist Dickkopf-1 and its receptors are coordinately regulated during early human adipogenesis. Journal of Cell Science 119 2613-2620. (doi:10. $1242 /$ jcs.02975)

Christodoulides C, Lagathu C, Sethi JK \& Vidal-Puig A 2009 Adipogenesis and WNT signalling. Trends in Endocrinology and Metabolism 20 16-24. (doi:10.1016/j.tem.2008.09.002)

Cypess AM, Lehman S, Williams G, Tal I, Rodman D, Goldfine AB, Kuo FC, Palmer EL, Tseng YH, Doria A et al. 2009 Identification and importance of brown adipose tissue in adult humans. New England Journal of Medicine 360 1509-1517. (doi:10.1056/NEJMoa0810780)

Grant SF, Thorleifsson G, Reynisdottir I, Benediktsson R, Manolescu A, Sainz J, Helgason A, Stefansson H, Emilsson V, Helgadottir A et al. 2006 Variant of transcription factor 7-like 2 (TCF7L2) gene confers risk of type 2 diabetes. Nature Genetics 38 320-323. (doi:10.1038/ ng1732)
Gustafson B, Eliasson B \& Smith U 2009 Thiazolidinediones increase the wingless-type MMTV integration site family (WNT) inhibitor Dickkopf-1 in adipocytes: a link with osteogenesis. Diabetologia 53 536-540. (doi:10.1007/s00125-009-1615-1)

Hagen T \& Vidal-Puig A 2002 Mitochondrial uncoupling proteins in human physiology and disease. Minerva Medica 93 41-57.

Horndasch M, Lienkamp S, Springer E, Schmitt A, Pavenstädt H, Walz G \& Gloy J 2006 The C/EBP homologous protein CHOP (GADD153) is an inhibitor of Wnt/TCF signals. Oncogene $\mathbf{2 5}$ 3397-3407. (doi:10.1038/sj.onc.1209380)

Kanazawa A, Tsukada S, Sekine A, Tsunoda T, Takahashi A, Kashiwagi A, Tanaka Y, Babazono T, Matsuda M, Kaku K et al. 2004 Association of the gene encoding wingless-type mammary tumor virus integrationsite family member 5B (WNT5B) with type 2 diabetes. American Journal of Human Genetics 75 832-843. (doi:10.1086/425340)

Kang S, Bajnok L, Longo KA, Petersen RK, Hansen JB, Kristiansen K \& MacDougald OA 2005 Effects of Wnt signaling on brown adipocyte differentiation and metabolism mediated by PGC-1 $\alpha$. Molecular and Cellular Biology 25 1272-1282. (doi:10.1128/MCB.25.4.1272-1282.2005)

Kawai M, Mushiake S, Bessho K, Murakami M, Namba N, Kokubu C, Michigami T \& Ozono K 2007 Wnt/Lrp/ $\beta$-catenin signaling suppresses adipogenesis by inhibiting mutual activation of PPAR $\gamma$ and $\mathrm{C} / \mathrm{EBP} \alpha$. Biochemical and Biophysical Research Communications 363 276-282. (doi:10.1016/j.bbrc.2007.08.088)

Kawano Y \& Kypta R 2003 Secreted antagonists of the Wnt signalling pathway. Journal of Cell Science 116 2627-2634. (doi:10.1242/jcs.00623)

Kennell JA \& MacDougald OA 2005 Wnt signaling inhibits adipogenesis through $\beta$-catenin-dependent and -independent mechanisms. Journal of Biological Chemistry 280 24004-24010. (doi:10.1074/jbc. M501080200)

Kennell JA, Gerin I, MacDougald OA \& Cadigan KM 2008 The microRNA miR-8 is a conserved negative regulator of Wnt signaling. PNAS 105 15417-15422. (doi:10.1073/pnas.0807763105)

Kintscher U, Hartge M, Hess K, Foryst-Ludwig A, Clemenz M, Wabitsch M, Fischer-Posovszky P, Barth TF, Dragun D, Skurk T et al. 2008 T-lymphocyte infiltration in visceral adipose tissue: a primary event in adipose tissue inflammation and the development of obesitymediated insulin resistance. Arteriosclerosis, Thrombosis, and Vascular Biology 28 1304-1310. (doi:10.1161/ATVBAHA.108.165100)

Kirton JP, Crofts NJ, George SJ, Brennan K \& Canfield AE 2007 Wnt/ $\beta$-catenin signaling stimulates chondrogenic and inhibits adipogenic differentiation of pericytes: potential relevance to vascular disease? Circulation Research 101 581-589. (doi:10.1161/ CIRCRESAHA.107.156372)

Klöting N, Fasshauer M, Dietrich A, Kovacs P, Schön MR, Kern M, Stumvoll M \& Blüher M 2010 Insulin-sensitive obesity. American Journal of Physiology. Endocrinology and Metabolism 299 E506-E515. (doi:10.1152/ajpendo.00586.2009)

Lagathu C, Christodoulides C, Virtue S, Cawthorn WP, Franzin C, Kimber WA, Nora ED, Campbell M, Medina-Gomez G, Cheyette BN et al. 2009 Dact1, a nutritionally regulated preadipocyte gene, controls adipogenesis by coordinating the Wnt/ $\beta$-catenin signaling network. Diabetes 58 609-619. (doi:10.2337/db08-1180)

Lagathu C, Christodoulides C, Tan CY, Virtue S, Laudes M, Campbell M, Ishikawa K, Ortega F, Tinahones FJ, Fernández-Real JM et al. 2010 Secreted frizzled-related protein 1 regulates adipose tissue expansion and is dysregulated in severe obesity. International Journal of Obesity 34 1695-1705. (doi:10.1038/ijo.2010.107)

Laudes M, Christodoulides C, Sewter C, Rochford JJ, Considine RV, Sethi JK, Vidal-Puig A \& O'Rahilly S 2004 Role of the POZ zinc finger transcription factor FBI-1 in human and murine adipogenesis. Journal of Biological Chemistry 279 11711-11718. (doi:10.1074/ jbc.M310240200)

Laudes M, Bilkovski R, Oberhauser F, Droste A, Gomolka M, Leeser U, Udelhoven M \& Krone W 2008 Transcription factor FBI-1 acts as a dual regulator in adipogenesis by coordinated regulation of cyclinA and E2F-4. Journal of Molecular Medicine 86 597-608. (doi:10.1007/ s00109-008-0326-2) 
Logan CY \& Nusse R 2004 The Wnt signaling pathway in development and disease. Annual Review of Cell and Developmental Biology 20 781-810. (doi:10.1146/annurev.cellbio.20.010403.113126)

Lyssenko V, Lupi R, Marchetti P, Del Guerra S, Orho-Melander M, Almgren P, Sjögren M, Ling C, Eriksson KF, Lethagen AL et al. 2007 Mechanisms by which common variants in the TCF7L2 gene increase risk of type 2 diabetes. Journal of Clinical Investigation 117 2155-2163. (doi:10.1172/JCI30706)

Okamura M, Kudo H, Wakabayashi K, Tanaka T, Nonaka A, Uchida A, Tsutsumi S, Sakakibara I, Naito M, Osborne TF et al. 2009 COUPTFII acts downstream of Wnt/ $\beta$-catenin signal to silence PPAR $\gamma$ gene expression and repress adipogenesis. PNAS 106 5819-5824. (doi:10.1073/pnas.0901676106)

Ouchi N, Higuchi A, Ohashi K, Oshima Y, Gokce N, Shibata R, Akasaki Y, Shimono A \& Walsh K 2010 Sfrp5 is an anti-inflammatory adipokine that modulates metabolic dysfunction in obesity. Science 329 454-457. (doi:10.1126/science.1188280)

Park JR, Jung JW, Lee YS \& Kang KS 2008 The roles of Wnt antagonists Dkk1 and sFRP4 during adipogenesis of human adipose tissuederived mesenchymal stem cells. Cell Proliferation 41 859-874. (doi:10.1111/j.1365-2184.2008.00565.x)

Rijsewijk F, Schuermann M, Wagenaar E, Parren P, Weigel D \& Nusse R 1987 The Drosophila homolog of the mouse mammary oncogene int- 1 is identical to the segment polarity gene wingless. Cell $\mathbf{5 0} 649-657$. (doi:10.1016/0092-8674(87)90038-9)

Rosen ED \& MacDougald OA 2006 Adipocyte differentiation from the inside out. Nature Reviews. Molecular Cell Biology 7 885-896. (doi:10. 1038/nrm2066)

Rosen ED \& Spiegelman BM 2000 Molecular regulation of adipogenesis. Annual Review of Cell and Developmental Biology 16 145-171. (doi:10.1146/annurev.cellbio.16.1.145)

Ross SE, Hemati N, Longo KA, Bennett CN, Lucas PC, Erickson RL \& MacDougald OA 2000 Inhibition of adipogenesis by Wnt signaling. Science 289 950-953. (doi:10.1126/science.289.5481.950)

Salpea KD, Gable DR, Cooper JA, Stephens JW, Hurel SJ, Ireland HA, Feher MD, Godsland IF \& Humphries SE 2009 The effect of WNT5B IVS3C $>\mathrm{G}$ on the susceptibility to type 2 diabetes in UK Caucasian subjects. Nutrition, Metabolism, and Cardiovascular Diseases 19 140-145. (doi:10.1016/j.numecd.2008.02.009)

Santos A, Bakker AD, de Blieck-Hogervorst JM \& Klein-Nulend J 2010 WNT5A induces osteogenic differentiation of human adipose stem cells via rho-associated kinase ROCK. Cytotherapy 12 924-932. (doi:10.3109/14653241003774011)

Savage DB, Petersen KF \& Shulman GI 2005 Mechanisms of insulin resistance in humans and possible links with inflammation. Hypertension 458 828-833. (doi:10.1161/01.HYP.0000163475.04421.e4)

Schilling T, Küffner R, Klein-Hitpass L, Zimmer R, Jakob F \& Schütze N 2008 Microarray analyses of transdifferentiated mesenchymal stem cells. Journal of Cellular Biochemistry 103 413-433. (doi:10.1002/ jcb.21415)

Scott LJ, Bonnycastle LL, Willer CJ, Sprau AG, Jackson AU, Narisu N, Duren WL, Chines PS, Stringham HM, Erdos MR et al. 2006 Association of transcription factor 7-like 2 (TCF7L2) variants with type 2 diabetes in a Finnish sample. Diabetes 55 2649-2653. (doi:10. 2337/db06-0341)

Scott LJ, Mohlke KL, Bonnycastle LL, Willer CJ, Li Y, Duren WL, Erdos MR, Stringham HM, Chines PS, Jackson AU et al. 2007 A genome-wide association study of type 2 diabetes in Finns detects multiple susceptibility variants. Science 316 1341-1345. (doi:10.1126/science.1142382)

Semenov MV, Habas R, Macdonald BT \& He X 2007 SnapShot: noncanonical Wnt signaling pathways. Cell 131 1378. (doi:10.1016/ j.cell.2007.12.011)
Sethi JK \& Hotamisligil GS 1999 The role of TNF alpha in adipocyte metabolism. Seminars in Cell Eं Developmental Biology 10 19-29. (doi:10.1006/scdb.1998.0273)

Sethi JK \& Vidal-Puig AJ 2007 Thematic review series: adipocyte biology. Adipose tissue function and plasticity orchestrate nutritional adaptation. Journal of Lipid Research 48 1253-1262. (doi:10. 1194/jlr.R700005-JLR200)

Sethi JK \& Vidal-Puig A 2010 Wnt signalling and the control of cellular metabolism. Biochemical Journal 427 1-17. (doi:10.1042/ BJ20091866)

Shang YC, Wang SH, Xiong F, Zhao CP, Peng FN, Feng SW, Li MS, Li Y \& Zhang C 2007a Wnt3a signaling promotes proliferation, myogenic differentiation, and migration of rat bone marrow mesenchymal stem cells. Acta Pharmacologica Sinica 28 1761-1774. (doi:10.1111/j.1745-7254.2007.00671.x)

Shang YC, Zhang C, Wang SH, Xiong F, Zhao CP, Peng FN, Feng SW, Yu MJ, Li MS \& Zhang YN $2007 b$ Activated $\beta$-catenin induces myogenesis and inhibits adipogenesis in BM-derived mesenchymal stromal cells. Cytotherapy 9 667-681. (doi:10.1080/ 14653240701508437)

Smith U 2007 TCF7L2 and type 2 diabetes - we WNT to know. Diabetologia 50 5-7. (doi:10.1007/s00125-006-0521-z)

Takada I, Mihara M, Suzawa M, Ohtake F, Kobayashi S, Igarashi M, Youn MY, Takeyama K, Nakamura T, Mezaki Y et al. 2007 A histone lysine methyltransferase activated by non-canonical Wnt signalling suppresses PPAR- $\gamma$ transactivation. Nature Cell Biology 9 1273-1285. (doi:10.1038/ncb1647)

Takemaru K, Yamaguchi S, Lee YS, Zhang Y, Carthew RW \& Moon RT 2003 Chibby, a nuclear $\beta$-catenin-associated antagonist of the Wnt/wingless pathway. Nature 422 905-909. (doi:10.1038/ nature01570)

Tseng YH, Kriauciunas KM, Kokkotou E \& Kahn CR 2004 Differential roles of insulin receptor substrates in brown adipocyte differentiation. Molecular and Cellular Biology 24 1918-1929. (doi:10.1128/ MCB.24.5.1918-1929.2004)

Wainwright BJ, Scambler PJ, Stanier P, Watson EK, Bell G, Wicking C, Estivill X, Courtney M, Boue A, Pedersen PS et al. 1988 Isolation of a human gene with protein sequence similarity to human and murine int-1 and the Drosophila segment polarity mutant wingless. EMBO Journal 7 1743-1748.

Wright WS, Longo KA, Dolinsky VW, Gerin I, Kang S, Bennett CN, Chiang SH, Prestwich TC, Gress C, Burant CF et al. 2007 Wnt10b inhibits obesity in ob/ob and agouti mice. Diabetes 56 295-303. (doi:10.2337/db06-1339)

Yoon JC, Ng A, Kim BH, Bianco A, Xavier RJ \& Elledge SJ 2010 Wnt signaling regulates mitochondrial physiology and insulin sensitivity. Genes and Development 24 1507-1518. (doi:10.1101/gad.1924910)

Zhang L, Gao X, Wen J, Ning Y \& Chen YG 2006 Dapper 1 antagonizes Wnt signaling by promoting dishevelled degradation. Journal of Biological Chemistry 281 8607-8612. (doi:10.1074/jbc.M600274200)

Zhou S, Eid K \& Glowacki J 2004 Cooperation between TGF- $\beta$ and Wnt pathways during chondrocyte and adipocyte differentiation of human marrow stromal cells. Journal of Bone and Mineral Research 19 463-470. (doi:10.1359/JBMR.0301239)

Zhou H, Mak W, Zheng Y, Dunstan CR \& Seibel MJ 2007 Osteoblasts directly control lineage commitment of mesenchymal progenitor cells through Wnt signalling. Journal of Biological Chemistry 283 1936-1945. (doi:10.1074/jbc.M702687200)

Received in final form 5 January 2011

Accepted 19 January 2011

Made available online as an Accepted Preprint 19 January 2011 